\title{
BMJ Open Poor prognosis of child and adolescent musculoskeletal pain: a systematic literature review
}

\author{
Negar Pourbordbari, Allan Riis, Martin Bach Jensen, ` Jens Lykkegaard Olesen, \\ Michael Skovdal Rathleff
}

To cite: Pourbordbari N, Riis $\mathrm{A}$, Jensen $\mathrm{MB}$, et al. Poor prognosis of child and adolescent musculoskeletal pain: a systematic literature review. BMJ Open 2019;9:e024921. doi:10.1136/ bmjopen-2018-024921

- Prepublication history and additional material for this paper are available online. To view these files, please visit the journal online (http://dx.doi. org/10.1136/bmjopen-2018024921).

Received 14 August 2018 Revised 2 April 2019

Accepted 25 June 2019

Check for updates

(c) Author(s) (or their employer(s)) 2019. Re-use permitted under CC BY-NC. No commercial re-use. See rights and permissions. Published by BMJ.

Center for General Practice at Aalborg University, Aalborg, Denmark

Correspondence to Dr Negar Pourbordbari; negar@dcm.aau.dk

\section{ABSTRACT}

Objectives To identify baseline patient characteristics that are (1) associated with a poor outcome on follow-up regardless of which treatment was provided (prognosis) or (2) associated with a successful outcome to a specific treatment (treatment effect modifiers).

Design Systematic literature review according to Preferred Reporting Items for Systematic Reviews and Meta-Analysis guidelines.

Data sources Medline, Embase, Cinahl, Web of Science, Cochrane, SportDiscus, OT Seeker and Psychinfo were searched for prospective cohort studies up to February 2019 without limitation in publication date.

Eligibility criteria Prospective cohort studies reporting either prognostic factors or treatment effect modifiers on persistent musculoskeletal pain in 0-year-old to 19-year-old children and adolescents. Pain caused by tumours, fractures, infections, systemic and neurological conditions were excluded. Outcome measures Our primary outcome was musculoskeletal pain at follow-up and identification of any baseline characteristics that were associated with this outcome (prognostic factors). No secondary outcomes were declared. Method Two reviewers independently screened abstracts and titles. We included prospective cohort studies investigating the prognosis or treatment effect modifiers of 0 -year-old to 19-year-old children and adolescents with self-reported musculoskeletal pain. Risk of bias assessment was conducted with the Quality in Prognostic Studies tool.

Results Twenty-six studies yielding a total of 111 unique prognostic factors were included. Female sex and psychological symptoms were the most frequent investigated prognostic factors. Increasing age, generalised pain, longer pain duration and smoking were other identified prognostic factors. No treatment effect modifiers were identified.

Conclusion Several prognostic factors are associated with a poor prognosis in children and adolescents with musculoskeletal pain. These prognostic factors may help guide clinical practice and shared decision-making. None of the included studies was conducted within a general practice setting which highlights an area in need of research. PROSPERO registration number CRD42016041378.

\section{INTRODUCTION}

General practice is often the point of first contact into the healthcare system and musculoskeletal pain complaints are the most common cause of contact. The case

\section{Strengths and limitations of this study}

This review is highly updated with a search up to February 2019.

- No previous review has aimed to identify prognostic factors in children and adolescents with musculoskeletal pain with the purpose of informing clinical practice.

- In collaboration with a research librarian, a highly sensitive search for each of the eight databases was developed to ensure an inclusion of the totality of previous research.

- Two reviewers independently carried out the screening and data extraction was executed in the same manner for all included studies.

- No meta-analysis was conducted due to a heterogeneity of patient population, setting and endpoints.

workload due to musculoskeletal pain complaints in children and adolescents is estimated to be $4 \%-8 \%$ of the UK general practice $^{1}$ and musculoskeletal pain is known to affect half of all children and adolescents, increasing exponentially in frequency around the age of 10 years. ${ }^{2-6} \mathrm{~A}$ recent systematic review reported that $40 \%$ of an adolescent population had experienced pain during the last 6 months. ${ }^{3}$ The most common pain sites are the knee and back. ${ }^{7}$ Musculoskeletal pain has a detrimental impact on the adolescents' quality of life and may cause them to withdraw from school, social and athletic activities. ${ }^{89}$

Musculoskeletal pain in children and adolescents has previously been considered a self-limiting condition without long-term impact. ${ }^{10}$ Recent cohort studies show that $16 \%-32 \%$ of patients with knee pain still report knee pain 1 year later ${ }^{10} 11$ and that $21 \%$ of 12 -year to 35 -year olds had persistent knee pain 6 years after initial contact to their general practitioner. ${ }^{10}$ Collectively, these studies highlight that a significant proportion of adolescents will report pain even years later. Who are the 
children and adolescents with a particularly high risk of long-lasting musculoskeletal pain? This is one of the most common questions from our stakeholder interviews with general practitioners (unpublished stakeholder event).

Knowledge of prognostic factors can inform the general practitioner of the prognosis of their patients and enable them to identify those with a poor prognosis to stratify care, address modifiable risk factors and better understand chronic pain conditions. The latest systematic review on prognostic factors for adolescents with musculoskeletal pain ${ }^{12}$ ended their literature search in July 2015 which makes for a timely update. So far, no systematic reviews have aimed to inform clinical practice of prognostic factors in children, and adolescents with musculoskeletal pain. Therefore, we aimed to identify baseline patient characteristics associated with a (1) poor outcome on follow-up (prognosis) or (2) successful outcome of a treatment (treatment effect modifiers).

\section{METHODS}

\section{Literature search}

We searched in Medline, Embase, Cinahl, Web of Science, Cochrane, SportDiscus, OT Seeker and PsychInfo from their inception until February 2019 without limitation on date. An experienced research librarian collaborated in the production of individual search strategies for each of the eight databases (see online supplementary appendix $1)$.

\section{Eligibility criteria}

\section{Study population and design}

We included prospective studies that investigated prognostic factors or treatment effect modifiers in children and adolescents 0-year to 19-year olds, with any type and location of musculoskeletal pain. Musculoskeletal pain was defined as pain in muscle, tendon, bone and joint. ${ }^{13}$ We included musculoskeletal pain types, reported in each of our included studies, without further definition of or changes in the designations chosen by the respective authors. We excluded pain knowingly caused by tumours, fractures, infections, systemic and neurological conditions, and stomach pain, because of insufficient differentiation between musculoskeletal stomach pain and stomach pain by other causes. Furthermore, we included all prospective studies, independent of intervention and randomised trials including all types of comparators. As expected, most studies did not use a comparator because they were prospective cohort studies. Similar to intervention, these studies were included independent of comparators. There were no restrictions on the type of setting or language.

\section{Review process}

Two reviewers (NP and AR) independently screened titles and abstracts for studies addressing the question: What are the prognostic factors and treatment effect modifiers for children and adolescents with musculoskeletal pain? Full-text articles were then screened, adding primary reasons for exclusion.

There was no blinding of the review authors to the journal titles, authors or institutions. Reference lists of all included studies were screened for eligible publications that may have been missed during the initial search. The study selection process was finalised without any disagreements on included studies. EndNote was used to remove duplicates and NP manually checked for duplicates afterwards.

\section{Data extraction}

Data for the included studies were extracted by NP in the form of: study characteristics (study design, recruitment setting and duration of follow-up), participant characteristics (musculoskeletal pain type, baseline age, study population and persistent pain at follow-up in females, males and combined) (table 1) and prognostic factors with their reported estimates: ORs, relative risks (RR), 95\% CI) and/or $p$ values. If possible, we extracted the adjusted associations.

Data were extracted with a predefined data extraction form inspired by The Cochrane Collaboration. ${ }^{14}$

\section{Outcomes and endpoints}

Our primary outcome of interest was musculoskeletal pain at follow-up. We wanted to identify any baseline characteristics that were associated with this outcome (prognostic factors). We used the term 'pain persistence' to describe participants who had pain at both baseline and follow-up, without applying restrictions on either pain measurement or on follow-up time points.

\section{Risk of bias}

Risk of bias was assessed using the Quality in Prognostic Studies (QUIPS) tool. ${ }^{15}$ On the study level, NP and AR independently rated the 26 included studies and reached consensus on all risk of bias assessments (table 2). Prognostic factors from studies with a high risk of bias, were excluded from figure 1 .

\section{Involvement of general practitioners}

With stakeholder involvement and input from a panel of general practice researchers experienced in musculoskeletal research, we subgrouped our identified prognostic factors in accordance with the biopsychosocial model ${ }^{1617}$ :

\section{Biological prognostic factors}

- Female sex.

- Older age.

- Body measurement factors.

- Physical functioning.

- Pain characteristics.

Psychological prognostic factors

- General psychological factors.

- Depressive factors. 


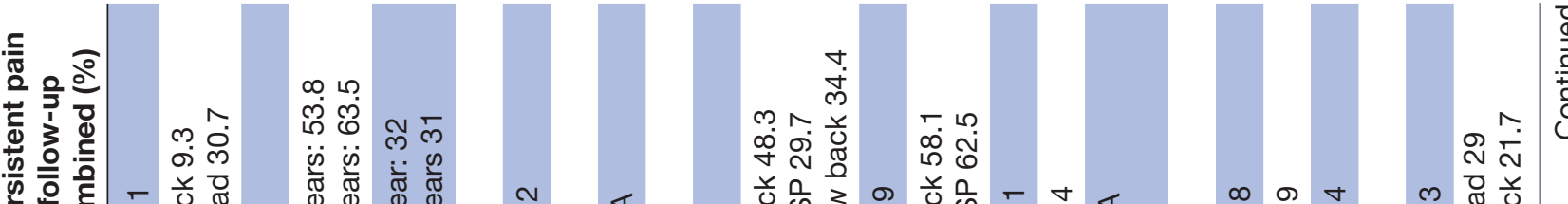

娄亲

$\frac{10}{90}$

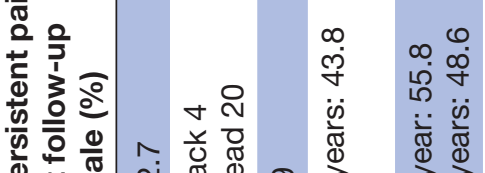

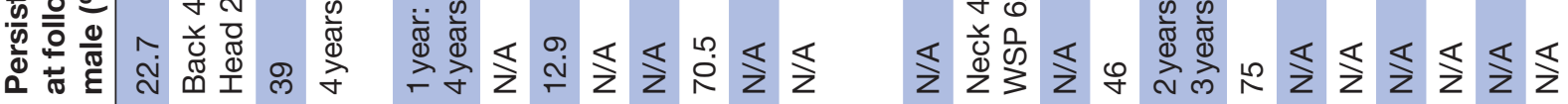

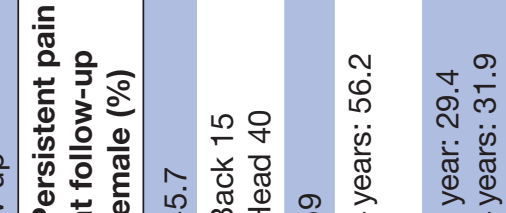

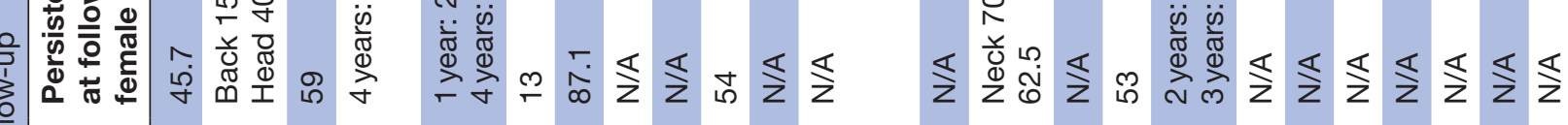

के

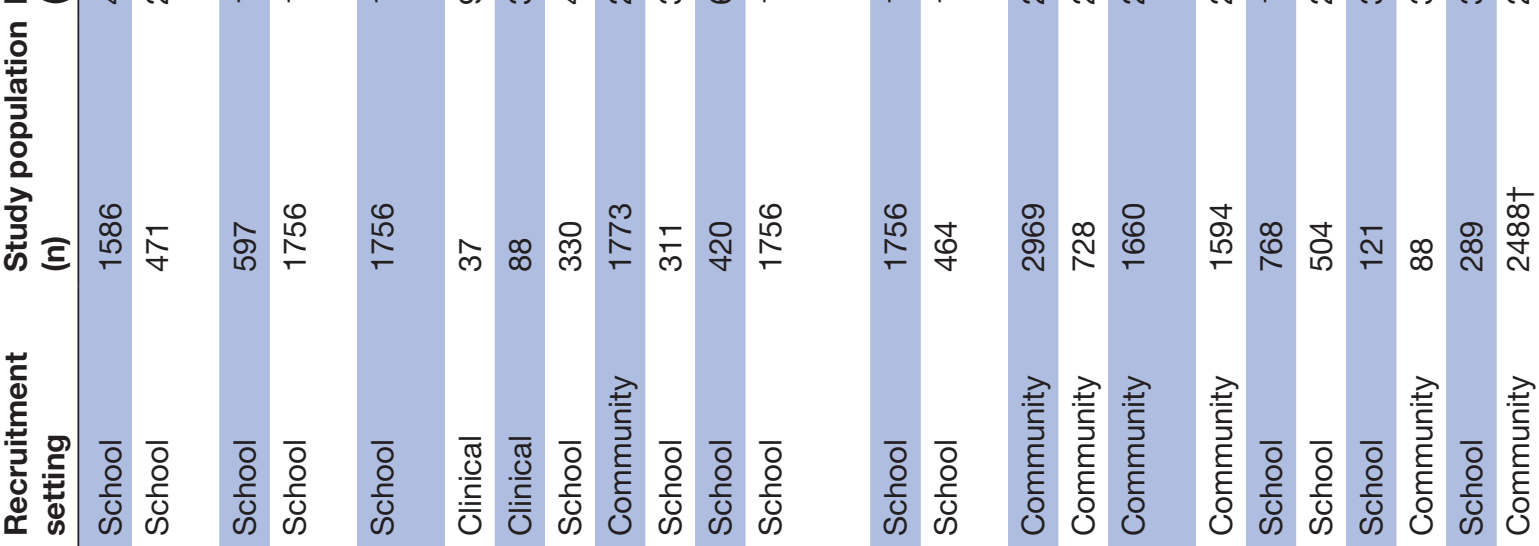

ঙ্ণ

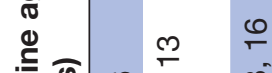

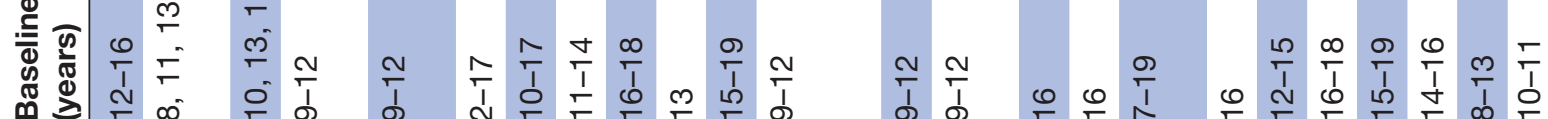

o

$\because \underset{1}{T}$

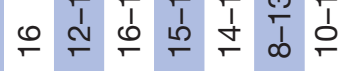

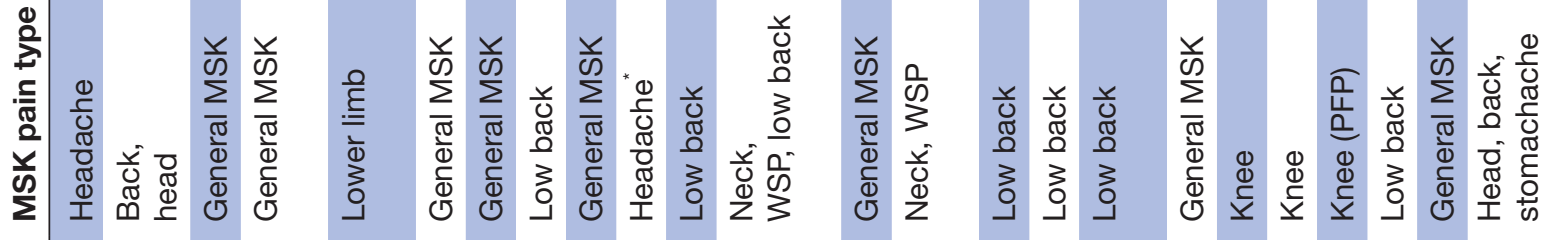




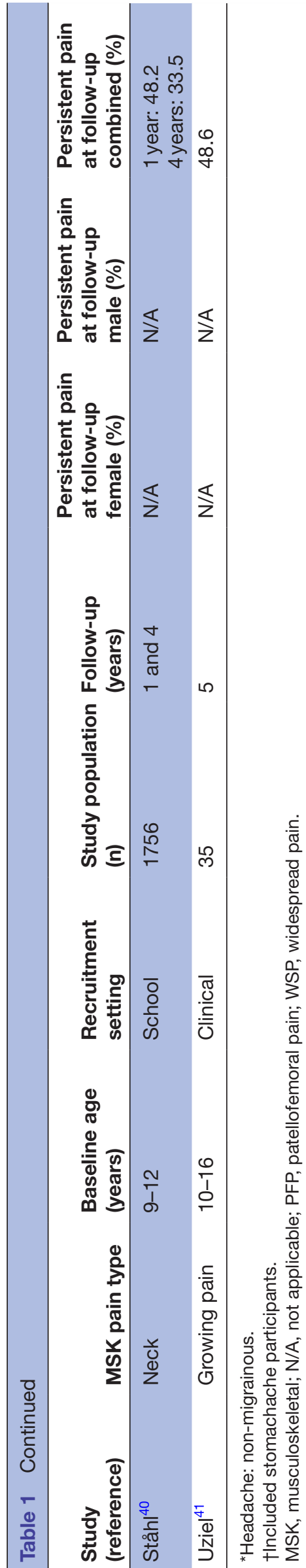

Social prognostic factors

- General social factors.

- Factors related to sleep/daytime tiredness.

- Physical activity/inactivity.

- Alcohol.

- Smoking.

\section{Reporting of results}

We were not able to conduct our a priori planned meta-analysis because of heterogeneity in terms of patient population, setting and time points for follow-up. The evidence on included prognostic factors was reported with ORs, RR and/or $p$ values. As OR and RR may differ in interpretation, we reported them separately. A statistically significant association between a patient characteristic and an outcome was defined as an RR or OR above or below 1 that did not include 1 in the $95 \%$ CI. As for $p$ value, a statistically significant association was defined as $p<0.05$. Average on pain at follow-up was calculated as average of individual studies reporting same musculoskeletal pain type at same follow-up duration (figure 2).

We used the Preferred Reporting Items for Systematic Reviews and Meta-Analyses checklist when writing our report $^{18}$ (see online supplementary appendix 2).

Patient and public involvement

No patients or public were involved in the present study.

\section{RESULTS}

\section{Included studies}

Figure 3 reports the results of the search strategy. Of the 48538 titles identified, 41735 studies were screened, and 26 studies $^{911} 17^{19-41}$ were included. All included studies were prospective studies. The included studies used a mix of different measures to capture pain at follow-up. Musculoskeletal pain types included in our search were general musculoskeletal pain, neck, back, lower back, lower limb, knee and growing pain. No treatment effect modifiers were identified.

Extracted data from the included studies: MSK pain type, baseline age, recruitment setting, size of study population, follow-up and percentage of study participants who represented persistent pain at follow-up, both stratified by gender and combined.

\section{Risk of bias}

The most common reasons for a moderate or high risk of bias were inadequately described study participation and statistical analyses $(n=6,23 \%)$, attrition rates $(n=5$, $20 \%)$ and poor adjustment for confounders $(n=11,42 \%)$. Three studies were rated with high risk of bias. With the purpose of filtering the results of prognostic factors, we excluded these studies from the final results depicted in figure 1 .

Risk of bias in included studies. With the QUIPS tool studies were assessed on the overall risk of bias within each of the six domains and rated as low, moderate or 


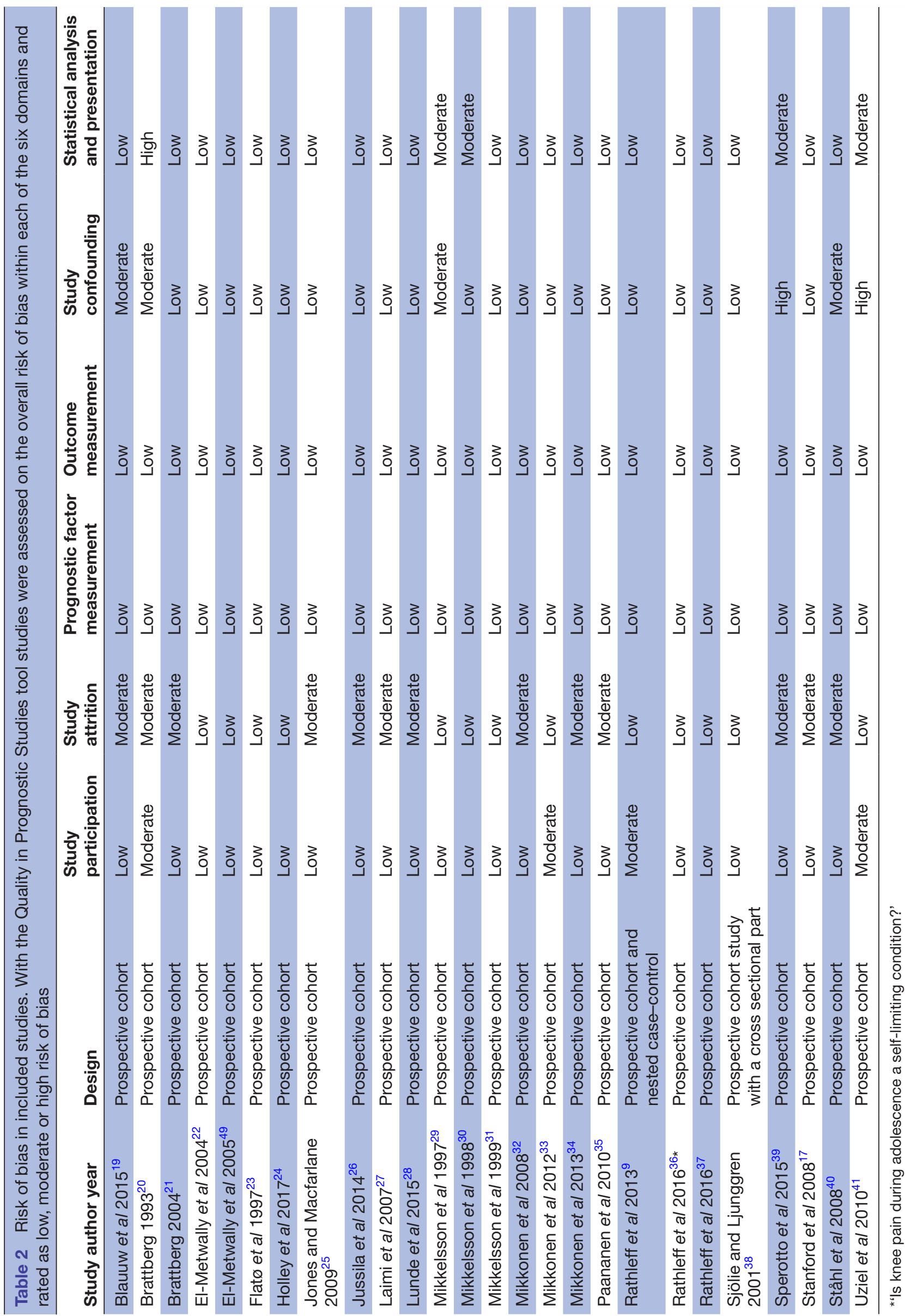

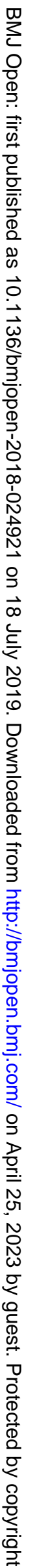




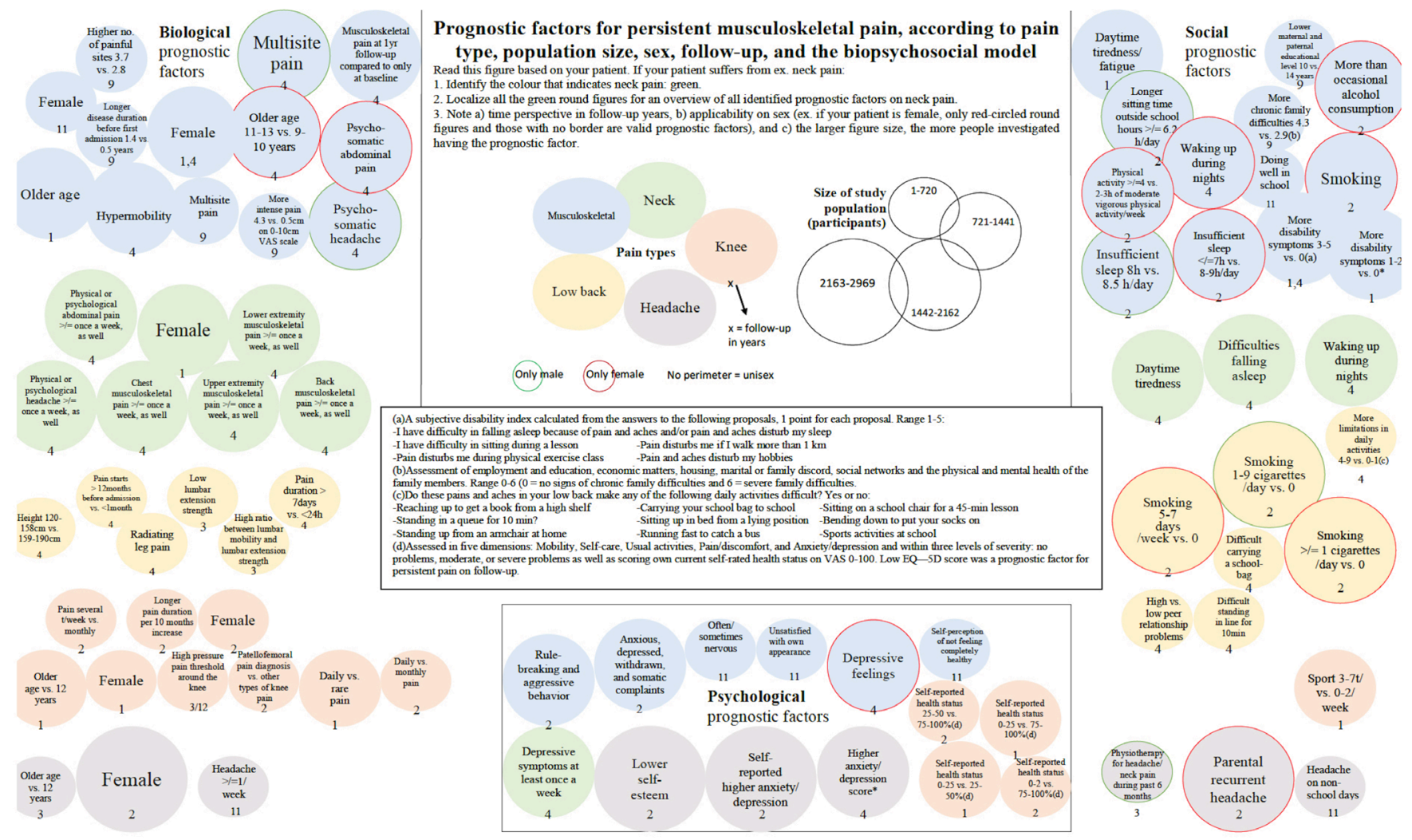

Figure 1 Prognostic factors for persistent musculoskeletal pain, according to pain type, population size, sex, follow-up and the biopsychosocial model.

high risk of bias. Three studies were rated with high risk of bias, and hence excluded from the final results.

\section{Prognosis}

Figure 2 highlights the persistence of musculoskeletal pain in all included studies at different follow-up time points and is calculated based on persistent pain at follow-up in table 1. At 1 year follow-up, an average of $54.4 \%$ with general musculoskeletal pain, an average of $41.8 \%$ with neck pain and $48.8 \%$ with knee pain reported pain. At 4-year follow-up, $63.5 \%$ with general musculoskeletal pain, $33.5 \%$ with neck pain and $26 \%$ with low back pain reported pain. At 9-year follow-up, 59\% with general musculoskeletal pain reported pain. A complete report of all the identified prognostic factors is listed in online supplementary table 1 . Figure 1 depicts the majority of these prognostic factors, stratified by pain type, sex, study population size and follow-up (please see online supplemental table 1 for explanatory notes).

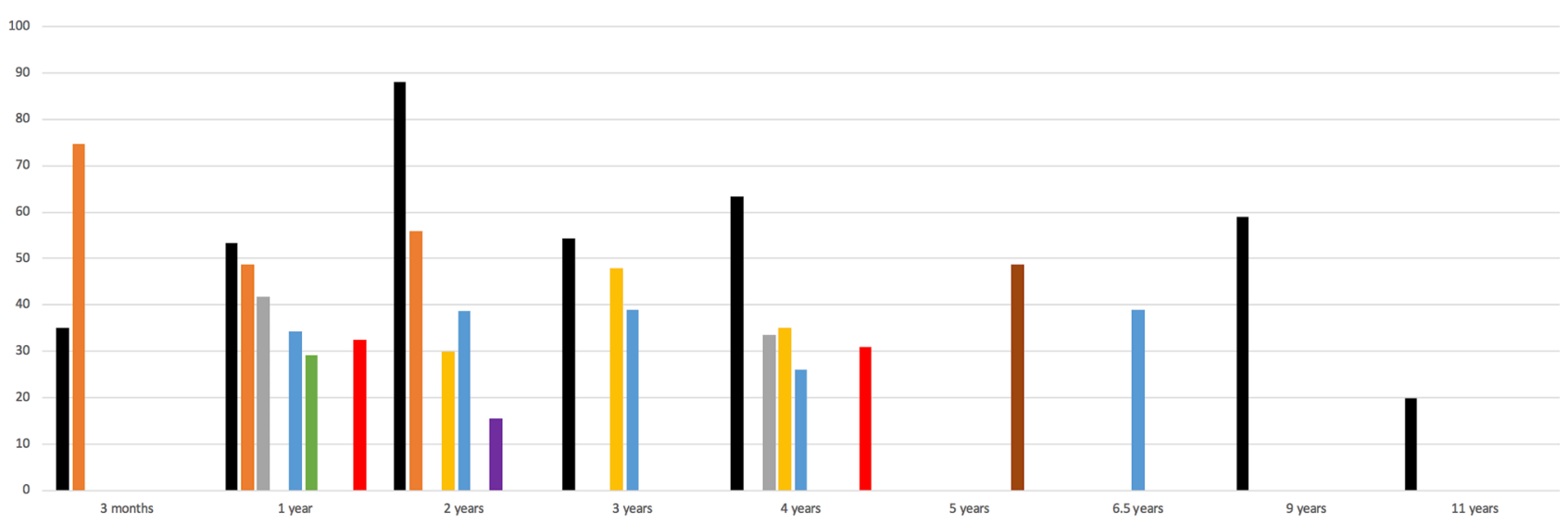

Figure 2 Persistent musculoskeletal pain, stratified in pain type and follow-up. The included studies investigated pain at follow-up time points ranging from 3 months to 11 years. General musculoskeletal pain (black) persisted in $>50 \%$ of participants after 1, 2, 3, 4 and 9 years of follow-up. 


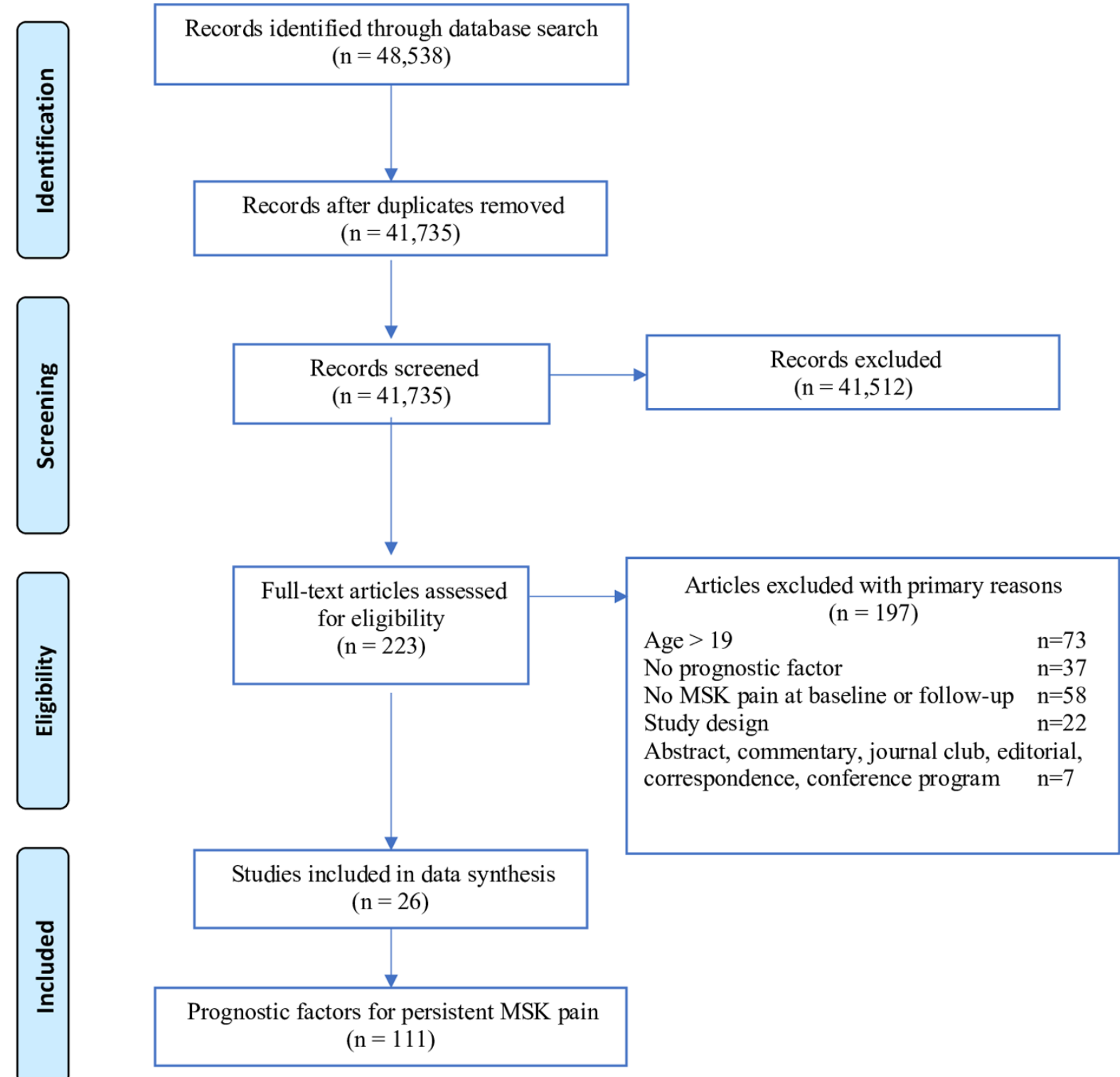

Figure 3 PRISMA flowchart presenting the flow of citations reviewed in the course of the systematic review. Forty-eight thousand five hundred and thirty-eight articles were identified through search in eight databases, resulting in 223 articles for fulltext eligibility screen and a final number of 26 studies for inclusion yielding 111 prognostic factors on musculoskeletal pain.

Very few prognostic factors were reported on back pain, growing pain, lower limb pain and widespread musculoskeletal pain (see online supplementary table 1); consequently, they were excluded from figure 1. Table 3 condenses the results from online supplementary table 1 and highlights four prognostic factors on four different musculoskeletal pain types. Below each factor are suggestive questions to provide the general practitioner with insight into the patient's prognosis. Table 3 and figure 1 can be printed and used by a general practitioner at time of initial consultation with a 0 -year-old to 19 year-old patient with musculoskeletal pain.

Please see the online supplementary file-video for an animation showing how our findings can be used in a clinical setting.

\section{Prognostic factors associated with pain at follow-up}

A total of 111 prognostic factors were associated with musculoskeletal pain at follow-up, of which most were on general musculoskeletal pain and low back pain (table 3). Online supplementary table 1 includes these results and further detailed depiction of prognostic factors.

Female sex was the most frequently identified prognostic factor associated with musculoskeletal pain at follow-up. Eleven studies identified psychological factors (eg, depression, anxiety and low self-esteem) to be associated with pain at follow-up in seven out of nine musculoskeletal pain types. ${ }^{9} 17192122252630353640$

Longer pain duration was associated with pain at follow-up across four musculoskeletal pain types: musculoskeletal, low back, knee and back pain. ${ }^{21} 232536$ 
Table 3 What to ask in clinical practice? Four prognostic factors belonging to four frequent musculoskeletal pain types in general practice: General musculoskeletal pain, low back pain, neck pain and knee pain. The questions are proposals towards assessment of prognosis on musculoskeletal pain

\begin{tabular}{|c|c|c|c|c|}
\hline & $\begin{array}{l}\text { General musculoskeletal } \\
\text { pain }\end{array}$ & Low back pain & Neck pain & Knee pain \\
\hline $\begin{array}{l}\text { Prognostic } \\
\text { factors }\end{array}$ & $\begin{array}{l}\text { Female sex and female } \\
\text { smokers. } \\
\text { Day tiredness/fatigue. } \\
\text { Physical activity versus } \\
\text { none. } \\
\text { Depressive symptoms. }\end{array}$ & $\begin{array}{l}\text { Higher lumbar } \\
\text { mobility.* } \\
\text { Longer pain duration. } \\
\text { Peer problems. } \\
\text { Smoking. }\end{array}$ & $\begin{array}{l}\text { Female sex. } \\
\text { Depressive symptoms. } \\
\text { Multisite pain versus } \\
\text { localised. } \\
\text { Day tiredness. }\end{array}$ & $\begin{array}{l}\text { Increasing age. } \\
\text { Daily pain. } \\
\text { Sport }>2 \mathrm{t} / \text { week. } \\
\text { Low quality of life. }\end{array}$ \\
\hline
\end{tabular}

${ }^{*}$ To be evaluated by clinical examination.

†This question is a suggestion for use in evaluation of quality of life.

$F$, female patients.

Five studies identified sleep-related problems associated with outcome. 2226303540

Other indicators for musculoskeletal pain at follow-up were increasing age, ${ }^{9} 222730$ smoking, ${ }^{32} 35$ parental pain $^{172341}$ and multisite pain. ${ }^{22} 2340$

Figure 1 summarises all identified prognostic factors for musculoskeletal pain at follow-up, stratified by pain type, study population size, sex and follow-up.

\section{Non-significant prognostic factors}

We identified a total of 134 patient characteristics across nine musculoskeletal pain types and different follow-up time points with a non-significant association with musculoskeletal pain at follow-up (see online supplementary table 1).

Increasing age 1121232829313641 was the most frequently identified baseline factor with a non-significant association to musculoskeletal pain at follow-up. Multiple studies reported non-significant evidence on higher body mass index 232628 and hypermobility. ${ }^{113040}$

\section{DISCUSSION}

\section{Principal findings}

Female sex was consistently associated with an increased risk (OR and RR between 1.24 and 3.66) of pain at follow-up across six different musculoskeletal pain types. Depressive symptoms,, 171922242630353640 factors related to sleep/daytime tiredness 2226303540 and parental pain condition $^{17} 2341$ were all associated with a higher risk of pain at follow-up. Collectively, the identified studies included prognostic factors across all aspects of the biopsychosocial model, despite a main focus on biological factors. Increasing age was identified as both a significant and a non-significant prognostic factor in the included studies. This conflicting finding reflects the uncertainty surrounding the importance of age as a prognostic factor. A complete overview of strength of associations can be found in online supplementary table 1 .

\section{Strengths and limitations in comparison with existing literature}

The latest systematic review on prognostic factors for children and adolescents with musculoskeletal pain ended their search in July 2015 which makes for a timely update. ${ }^{12}$ In addition to adding newer studies, our review differs from the previous with search in more databases, no restriction on publication language and no restriction on pain duration. ${ }^{41}$ Furthermore, this review is highly updated with a search up to February 2019 and the protocol for this review was developed using the Preferred Reporting Items for Systematic Review and Meta-Analysis Protocols 2015 statement (see online supplementary appendix 3). Despite methodology differences, we did not identify additional studies from inception to 2015, but identified three new studies from January 2016 to 2017. These studies added important knowledge of female sex, pain frequency and the prognosis of knee pain and general musculoskeletal pain. Thereby, supporting the previous research. Despite the commonality of children and adolescents with musculoskeletal pain in general practice, ${ }^{6}$ we did not identify a single study with a population of children or adolescents recruited from general practice.

A previous review on prognostic factors for adults with musculoskeletal pain in primary care was published in $2017^{42}$ with findings similar to ours, that is, female gender, older age, depression/anxiety and long pain duration were found associated with an increased risk of 
musculoskeletal pain at follow-up. This suggest that some of the prognostic factors function well across the age range and their use is not isolated to specific age groups.

\section{Explanation of findings and implications for clinical practice}

Our findings suggest that females are at higher risk of persistent pain. Previous research highlights potential sex differences in pain responses by assessing pain intensity and threshold and conclude that females display greater sensitivity to multiple pain modalities compared with males. ${ }^{43}$ Importantly, pain-coping strategies have been found to differ between the sexes. ${ }^{44}{ }^{45}$ Females make use of social support, cognitive reinterpretation and positive self-statements, while males use behavioural distraction and problem-focused tactics to manage pain. This could partly explain the sex-difference in prognosis and may open new opportunities for targeted treatment to improve long-term outcomes of young females with musculoskeletal pain.

The current results point towards both modifiable (psychological factors, smoking and peer problems) and non-modifiable (sex, age and pain duration) factors associated with prognosis. Despite time constraints in general practice, most of these factors can be extracted from electronic stored patient data, psychometric tests and examination in a clinical general practice setting.

By asking your patient a few questions at the first consultation of musculoskeletal pain, the general practitioner may improve their understanding of their patients' risk of pain in the future. In the case of a present, baseline factor with a poor prognosis, for example, smoking among low back pain patients, the general practitioner now both has a scientific reason for and the clinical tool to modulate this factor. By prescribing cessation of smoking, thus, making an effort to improve the outcome for this patient.

Treatment of musculoskeletal pain requires the general practitioner to apply a multifactorial rather than a singlefactor approach, hence, including the entire person and their life circumstances when treating patients with pain. ${ }^{164647}$ Clinicians must be aware of the multifactorial aetiology and consider biological, psychological and social factors of musculoskeletal pain when addressing patient's coping behaviour and cognitive appraisal. ${ }^{48}$

\section{Implications for future research}

Most of our included studies investigated biological prognostic factors (54 factors). Fewer investigated social (35 factors) and even fewer psychological prognostic factors (22 factors). Future research should include the entire patient, in terms of biological, psychological and social-related components and aim to study these prognostic factors in a general practice setting. There is a dearth of knowledge of how psychosocial factors are associated with prognosis and how general practitioners can harness this information to tailor treatment and information to their patients. Despite the potential importance of pain, 'who' the patient is should not be discounted. Geographical location of home, parental pain, profession and income, and social identity in terms of cultural differences, religious beliefs and relations could be important because we know from the biopsychosocial model that social background is important in relation to pain coping.

Only one study did follow-up after 4, 6.5, 9 and 11 years, respectively, which highlights the lack of long-term cohort studies on prognosis and impact of musculoskeletal pain in youth.

Almost one in every two children and adolescents still reported pain even years later. ${ }^{10} 1149$ This highlights the importance of prognosis of pain in children and adolescents. Healthcare practitioners should be cognisant not to assume that musculoskeletal pain during childhood or adolescence is transient or self-limiting.

Contributors NP conducted the systematic literature search. NP and AR independently carried out the screening, study inclusion and study bias assessment. NP and MSR led writing of both the protocol and manuscript and all authors NP, AR, MSR, MBBJ and JLO contributed with important reflections and revisions to both.

Funding This work was supported by The Research Unit for General Practice in Aalborg, Denmark, without any further funders.

Competing interests None declared.

Patient consent for publication Not required.

Provenance and peer review Not commissioned; externally peer reviewed.

Data sharing statement All data and results presented within this systematic review can be obtained, on reasonable request, by contacting the corresponding author.

Open access This is an open access article distributed in accordance with the Creative Commons Attribution Non Commercial (CC BY-NC 4.0) license, which permits others to distribute, remix, adapt, build upon this work non-commercially, and license their derivative works on different terms, provided the original work is properly cited, appropriate credit is given, any changes made indicated, and the use is non-commercial. See: http://creativecommons.org/licenses/by-nc/4.0/.

\section{REFERENCES}

1. Michaleff ZA, Campbell P, Protheroe J, et al. Consultation patterns of children and adolescents with knee pain in UK general practice: analysis of medical records. BMC Musculoskelet Disord 2017;18:239.

2. Höfel L, Draheim N, Häfner R, et al. [Pain syndrome of the musculoskeletal system in children and adolescents]. Z Rheumatol 2016;75:292-301.

3. King S, Chambers CT, Huguet A, et al. The epidemiology of chronic pain in children and adolescents revisited: a systematic review. Pain 2011;152:2729-38.

4. Auvinen JP, Paananen MV, Tammelin TH, et al. Musculoskeletal pain combinations in adolescents. Spine 2009;34:1192-7.

5. De Inocencio J. Epidemiology of musculoskeletal pain in primary care. Arch Dis Child 2004;89:431-4.

6. Michaleff ZA, Kamper SJ, Stinson JN, et al. Measuring Musculoskeletal Pain in Infants, Children, and Adolescents. J Orthop Sports Phys Ther 2017;47:712-30.

7. Smedbråten BK, Natvig B, Rutle $O$, et al. Self-reported bodily pain in schoolchildren. Scand J Rheumatol 1998;27:273-6.

8. McGrath P. Psychological guidelines for helping children cope with chronic benign intractable pain. The Clinical journal of pain 1986.

9. Rathleff CR, Olesen JL, Roos EM, et al. Half of 12-15-year-olds with knee pain still have pain after one year. Dan Med J 2013;60:A4725.

10. Kastelein M, Luijsterburg PA, Heintjes EM, et al. The 6-year trajectory of non-traumatic knee symptoms (including patellofemoral pain) in adolescents and young adults in general practice: a study of clinical predictors. Br J Sports Med 2015;49:400-5.

11. El-Metwally A, Salminen JJ, Auvinen A, Kautiainen H, Mikkelsson M. Lower Limb Pain in a Preadolescent Population: Prognosis and Risk Factors for Chronicity--A Prospective 1- and 4-Year Follow-up Study. Pediatrics 2005;116:673-81. 
12. Huguet A, Tougas ME, Hayden J, et al. Systematic review with metaanalysis of childhood and adolescent risk and prognostic factors for musculoskeletal pain. Pain 2016;157:2640-56.

13. Treede R-D, Rief W, Barke A, et al. A classification of chronic pain for ICD-11. Pain 2015:1.

14. Effective Practice and Organization of Care (EPOC). Data collection form. EPOC Resources for review authors. Oslo: Norwegian Knowledge Centre for the Health Services; 2013.. 2013 http://epoc. cochrane.org/epoc-specific-resources-review-authors.

15. Hayden JA, van der Windt DA, Cartwright JL, et al. Assessing bias in studies of prognostic factors. Ann Intern Med 2013;158:280-6.

16. Engel $\mathrm{G}$. The need for a new medical model: a challenge for biomedicine. Science 1977;196(4286):129-36.

17. Stanford EA, Chambers CT, Biesanz JC, et al. The frequency, trajectories and predictors of adolescent recurrent pain: a population-based approach. Pain 2008;138:11-21.

18. Moher D, Liberati A, Tetzlaff J. Preferred reporting items for systematic reviews and meta-analyses: the PRISMA statement. PLoS Med 2009:10.1371/journal.pmed.1000097.

19. Blaauw BA, Dyb G, Hagen K, et al. The relationship of anxiety, depression and behavioral problems with recurrent headache in late adolescence - a Young-HUNT follow-up study. J Headache Pain 2015;16:1-7.

20. Brattberg G. Back pain and headache in Swedish schoolchildren: A longitudinal study. Pain Clinic 1993;6:157-62.

21. Brattberg $G$. Do pain problems in young school children persist into early adulthood? A 13-year follow-up. Eur J Pain 2004;8:187-99.

22. El-Metwally A, Salminen JJ, Auvinen A, et al. Prognosis of nonspecific musculoskeletal pain in preadolescents: a prospective 4-year follow-up study till adolescence. Pain 2004;110:550-9.

23. Flatø $\mathrm{B}$, Aasland $\mathrm{A}$, Vandvik $\mathrm{IH}$, et al. Outcome and predictive factors in children with chronic idiopathic musculoskeletal pain. Clin Exp Rheumatol 1997;15:569-77.

24. Holley AL, Wilson AC, Palermo TM. Predictors of the transition from acute to persistent musculoskeletal pain in children and adolescents: a prospective study. Pain 2017;158:794-801.

25. Jones GT, Macfarlane GJ. Predicting persistent low back pain in schoolchildren: a prospective cohort study. Arthritis Rheum 2009;61:1359-66.

26. Jussila L, Paananen M, Näyhä S, et al. Psychosocial and lifestyle correlates of musculoskeletal pain patterns in adolescence: a 2-year follow-up study. Eur J Pain 2014;18:139-46.

27. Laimi K, Vahlberg T, Salminen J, et al. Does neck pain determine the outcome of adolescent headache? Cephalalgia 2007;27:244-53.

28. Lunde LK, Koch M, Hanvold TN, et al. Low back pain and physical activity - A 6.5 year follow-up among young adults in their transition from school to working life. BMC Public Health 2015;15:1115.

29. Mikkelsson M, Salminen JJ, Kautiainen H. Non-specific musculoskeletal pain in preadolescents. Prevalence and 1-year persistence. Pain 1997;73:29-35

30. Mikkelsson M, Salminen JJ, Sourander A, et al. Contributing factors to the persistence of musculoskeletal pain in preadolescents: a prospective 1-year follow-up study. Pain 1998;77:67-72.

31. Mikkelsson M, Sourander A, Salminen JJ, et al. Widespread pain and neck pain in schoolchildren. A prospective one-year follow-up study. Acta Paediatr 1999;88:1119-24.
32. Mikkonen P, Leino-Arjas P, Remes J, et al. Is smoking a risk factor for low back pain in adolescents? A prospective cohort study. Spine 2008;33:527-32.

33. Mikkonen P, Viikari-Juntura E, Remes J, et al. Physical workload and risk of low back pain in adolescence. Occup Environ Med 2012;69.

34. Mikkonen PH, Laitinen J, Remes J, et al. Association between overweight and low back pain: a population-based prospective cohort study of adolescents. Spine 2013;38:1026-33.

35. Paananen MV, Taimela SP, Auvinen JP, et al. Risk factors for persistence of multiple musculoskeletal pains in adolescence: a 2-year follow-up study. Eur J Pain 2010;14:1026-32.

36. Rathleff MS, Rathleff CR, Olesen JL, et al. Is Knee Pain During Adolescence a Self-limiting Condition? Prognosis of Patellofemora Pain and Other Types of Knee Pain. Am J Sports Med 2016:44:1165-71.

37. Rathleff MS, Roos EM, Olesen JL, et al. Self-reported Recovery is Associated With Improvement in Localized Hyperalgesia Among Adolescent Females With Patellofemoral Pain: Results From a Cluster Randomized Trial. Clin J Pain 2016;32:428-34.

38. Sjölie AN, Ljunggren AE. The significance of high lumbar mobility and low lumbar strength for current and future low back pain in adolescents. Spine 2001;26:2629-36

39. Sperotto F, Brachi S, Vittadello F, et al. Musculoskeletal pain in schoolchildren across puberty: a 3-year follow-up study. Pediatr Rheumatol Online J 2015;13:16.

40. Ståhl M, Kautiainen H, El-Metwally A, et al. Non-specific neck pain in schoolchildren: prognosis and risk factors for occurrence and persistence. A 4-year follow-up study. Pain 2008;137:316-22.

41. Uziel Y, Chapnick G, Jaber L, et al. Five-year outcome of children with "growing pains": correlations with pain threshold. J Pediatr 2010;156:838-40.

42. Artus M, Campbell P, Mallen CD, et al. Generic prognostic factors for musculoskeletal pain in primary care: a systematic review. BMJ Open 2017;7:e012901.

43. Bartley EJ, Fillingim RB. Sex differences in pain: a brief review of clinical and experimental findings. Br J Anaesth 2013;111:52-8.

44. Fillingim RB, King CD, Ribeiro-Dasilva MC, et al. Sex, gender, and pain: a review of recent clinical and experimental findings. J Pain 2009;10:447-85

45. Racine M, Tousignant-Laflamme $Y$, Kloda LA, et al. A systematic literature review of 10 years of research on sex/gender and pain perception - part 2: do biopsychosocial factors alter pain sensitivity differently in women and men? Pain 2012;153:619-35.

46. Polatin P, Bevers K, Gatchel RJ. Pharmacological treatment of depression in geriatric chronic pain patients: a biopsychosocial approach integrating functional restoration. Expert Rev Clin Pharmacol 2017;10:957-63.

47. Shams Amiri R, Faghih Jouibari M, Nejat F, et al. Iniencephaly: clinical, radiological and surgical findings. Pediatr Neurosurg 2010;46:290-3

48. Gatchel RJ, Peng YB, Peters ML, et al. The biopsychosocial approach to chronic pain: scientific advances and future directions Psychol Bull 2007;133:581-624.

49. El-Metwally A, Salminen JJ, Auvinen A, et al. Lower limb pain in a preadolescent population: prognosis and risk factors for chronicity--a prospective 1- and 4-year follow-up study. Pediatrics 2005;116:673-81. 